\title{
Slurry Erosion Characteristics of Stellite 6 on AISI 316 and AISI 410 Stainless Steels
}

\author{
B. Mousavi*, , M. S. Shakeri* and A. Shamsipoor* \\ *Materials and Energy Research Center (MERC), Meshkindasht, Karaj, P.O. Box 31787-316, Iran \\ †Corresponding author : b.mousavi1986@gmail.com \\ (Received June 21, 2020 ; Revised August 12, 2020 ; Accepted October 6, 2020)
}

\begin{abstract}
In this study, we explored the microstructure and slurry erosion properties of Stellite 6 cladding deposited on AISI316 and AISI410 stainless steel substrates using gas tungsten arc welding (GTAW), also known as tungsten inert gas (TIG) welding. Optical microscopy (OM), scanning electron microscopy (SEM), and energy-dispersive spectroscopy (EDS) were employed to analyze the microstructure similar to the erosion mechanisms. X-ray diffraction (XRD) analysis was performed to identify the phases formed in the coating. The results revealed that the microstructure of the coating consisted of carbides embedded in a Co-rich solid solution. The coated samples exhibited higher erosion resistance than bare steel and this feature can postpone the failure and extend the life time of industrial component. Furthermore, a noticeable corrosion influence on the erosion behavior of the coating was identified. A higher erosion resistance of the coating was obtained for the AISI 316 substrate because of its better response to the corrosive attack. Finally, a brittle mode of the erosion behavior was detected for the Stellite coating.
\end{abstract}

Key Words : Stellite, Stainless steel, Slurry erosion, Welding

\section{Introduction}

Slurry erosion is a complicated phenomenon due to the effects of different parameters related to target material, the process and the environment ${ }^{1,2)}$. One of the methods to improve the erosion resistance is formation of coating on the metallic substrates. Cobalt-based super alloys such as Stellite are used as coating in the environments with high corrosiveness and erosion due to high hardness and corrosion resistance ${ }^{3,4}$. The formation of carbides in the matrix along with solid solution hardening are known as two major mechanisms for increasing the erosion resistance in these alloys ${ }^{5}$. Several works have been done about the deposition of hard coatings on steel substrates by different methods e.g. Gas Tungsten Arc Welding (GTAW) and laser welding ${ }^{4-7)}$. Gholipour et al. ${ }^{7)}$ applied the Stellite 6 cladding onto 17-4 PH stainless steel using GTAW and studied the microstructure and the erosion properties of the coating.They showed that applying an inter-layer between the metal substrate and the coating could improve the erosion properties of the coating. Xuet al. ${ }^{8)}$ applied the Stellite 6 cladding to STS 403 martensitic stainless steel using both GTAW and laser welding. They have investigated microstructure, distribution of alloying elements and compared the hardness and the erosion properties of the coating. The results showed that usage of laser welding led to narrow heat affected zone, improved hardness, finer microstructure and higher erosion resistance in compared with those obtained from GTAW. However, there are practically simpler and more cost-effective methods like gas tungsten arc welding in which discreet controlling of welding parameters, Enhanced surface and wear properties can be achieved ${ }^{7}$. Hattori et al. ${ }^{9)}$ compared the cavitation erosion resistances of Stellite 6 and Stellite 21 claddings with that of for AISI 304 stainless steel. They showed that the cavitation erosion resistance of the coating depends on its hardness. Jendrzejewski et al. ${ }^{10)}$ applied Stellite cladding to Ti plates using laser welding and reported the dependence of the hardness on the distance from the coating surface. The effect of angle of impingement on the slurry erosion of the Stellite cladding was studied by Romoet. $\mathrm{Al}^{11}{ }^{11}$. They showed that the maximum erosion resistance was achieved at 
the impact angle of 15 degree while the maximum weight loss was obtained at 45 degree.

There is no report on comparing the slurry erosion of Stellite 6 cladding on two different substrates with the effect of corrosive medium and distribution of the alloying elements on the coating. Moreover, angle impact effect on the coating, weight loss and study of mechanisms of erosion has not been completely reported in the previous literatures.

The Substrates used in this investigation are applied in oil and gas industries. Hence, Corrosion and erosion of valves and pipes is the main factor affecting the lifetime of equipment. So the aim of this investigation is to evaluate the various characteristics of Stellite 6 coating on the substrates in order to improve the surface features for increasing workability of specimens.

\section{Experimental Procedure}

Plates of AISI austenitic stainless and AISI410 martensitic stainless steels with the dimensions of $18 \times 200 \times$ $300 \mathrm{~mm}$ as metal substrates were cut. For cleaning and degreasing, they were first immersed in acetone and then were rinsed with warm water. Stellite 6 alloy was employed as cladding material in the form of wire with the diameter of $3 \mathrm{~mm}$. The chemical compositions of the substrate steels and the Stellite cladding are shown in Table 1.

Before applying the coating, the substrate metals were preheated for 2 hours at $250^{\circ} \mathrm{C}$ inside the furnace and after few minutes the coating was applied using GTAW. The welding parameters are presented in Table 2.

For microstructural studies, transverse sections were cut from the coating samples. They were studied after preparation by metallographic procedures. For comparison, an uncoated sampled from each substrate steels were prepared. For microstructural investigations, after grounding and polishing, chemical etching was conducted. Glycergia, Villela and Marbel solutions were used to
Table 2 GTAW welding parameters

\begin{tabular}{|c|c|}
\hline lectrode diameter $(\mathrm{mm})$ & 3 \\
\hline Current type & Direct with positive polarity \\
\hline Current intensity (A) & 200 \\
\hline Welding speed (m/s) & $1.5 \times 10^{-3}$ \\
\hline Argon flow (liter $/ \mathrm{min})$ & 10 \\
\hline Voltage $(\mathrm{V})$ & 28 \\
\hline Feed rate $\left(\mathrm{cm} . \mathrm{min}^{-1}\right)$ & 25 \\
\hline Arc length $\left(\mathrm{mm}^{-1}\right)$ & 5 \\
\hline Tungsten tip angle (degree) & 60 \\
\hline Electrode angle(vertical) & 15 \\
\hline
\end{tabular}

etch the austenitic and the martensitic steels and the coating, respectively. Microstructural studies were done using optical microscope (MEIGI-ML7100), Scanning Electron Microscope (SEM, Tescan VEGAII XMU) equipped with E.D.S analyzer and X-ray Diffraction (XRD, X'Pert Pro MPD, PANalytical). To determine hardness profile, microhardness measurements were carried out using Buheler-MXT-al instrument with a $100 \mathrm{~g}$ force on the transverse sections. Slurry erosion test was conducted according to ASTM G73 in the ambient temperature. The used slurry contained water with 10 vol. \% quartz particles in the range of 200-300 nm. Table 3 shows the erosion test parameters. In order to conduct the test, several samples with the dimensions of $17 * 10 * 10$ were prepared. Nozzle distance to surface was $5 \mathrm{~mm}$ and the Impingement speed was set at $12 \mathrm{~m} / \mathrm{s}$. The erosion test results were reported based on the weight loss measurement in the drying condition by a 0.0001 precision scale. To study the effect of corrosion, erosion test combined with corrosion was done. To perform this test, water containing $3.5 \% \mathrm{NaCl}$ was prepared and the other conditions were selected similar to those in the erosion test. To investigate the angle of impingement, the erosion test was carried out at three angles of 30 degree, 60 degree and 90 degree and the weight loss values at different angle of impingements

Table 1 Chemical compositions of AISI316 and AISI410 stainle ss steels and stellite cladding (wt. \%)

\begin{tabular}{|c|c|c|c|c|c|c|c|c|c|}
\hline $\mathrm{Fe}$ & $\mathrm{C}$ & $\mathrm{Mn}$ & $\mathrm{Mo}$ & $\mathrm{Ni}$ & $\mathrm{W}$ & $\mathrm{Si}$ & $\mathrm{Cr}$ & $\mathrm{Co}$ & \\
\hline $\mathrm{Bal}$ & $03 / 0$ & $50 / 1$ & $17 / 2$ & $03 / 10$ & - & $56 / 0$ & $7 / 17$ & - & AISI 316 \\
\hline $\mathrm{Bal}$ & $1 / 0$ & $96 / 0$ & - & $52 / 0$ & $03 / 0$ & $03 / 0$ & $06 / 11$ & - & AISI 410 \\
\hline $98 / 2$ & $2 / 1$ & $46 / 0$ & - & $42 / 2$ & $26 / 4$ & 1 & $41 / 28$ & Bal. & Stellite 6 \\
\hline
\end{tabular}

Table 3 Slurry erosion testing parameters

\begin{tabular}{|c|c|c|c|c|c|}
\hline $\begin{array}{c}\text { Test temperature } \\
\left({ }^{\circ} \mathrm{C}\right)\end{array}$ & $\begin{array}{c}\text { Impingement } \\
\text { speed }(\mathrm{m} / \mathrm{s})\end{array}$ & $\begin{array}{c}\text { Impinging } \\
\text { medium }\end{array}$ & $\begin{array}{c}\text { Angle of impinge- } \\
\text { ment (degree) }\end{array}$ & $\begin{array}{c}\text { Nozzle distance } \\
\text { to surface }(\mathrm{mm})\end{array}$ & $\begin{array}{c}\text { Erosion time } \\
(\mathrm{min})\end{array}$ \\
\hline $30 \pm 2$ & 12 & $\mathrm{H}_{2} \mathrm{O}+\mathrm{SiO}_{2}(+\mathrm{NaCl})$ & $30,60,90$ & 5 & 60 \\
\hline
\end{tabular}


were compared. Finally, SEM was employed to analyze the erosion mechanisms.

\section{Results and discussion}

\subsection{Microstructural investigation}

Fig. 1 shows the Optical Microscopy and SEM images of the microstructure of martensitic and austenitic substrate.
Fig. 2 shows SEM and OM images of the interface between substrates (martensitic and Austenitic stainless steel) and Coating (Stellite cladding).

It is clear that cellular growth initiates at the interface. With increasing the distance from the interface and changing the thermal gradient $(\mathrm{G})$ as same as the solidification rate $(\mathrm{R})$, constitutional super-cooling will be increased. It results in conversion of cellular growth to dendritic growth. It is worth to be mentioned that pla-
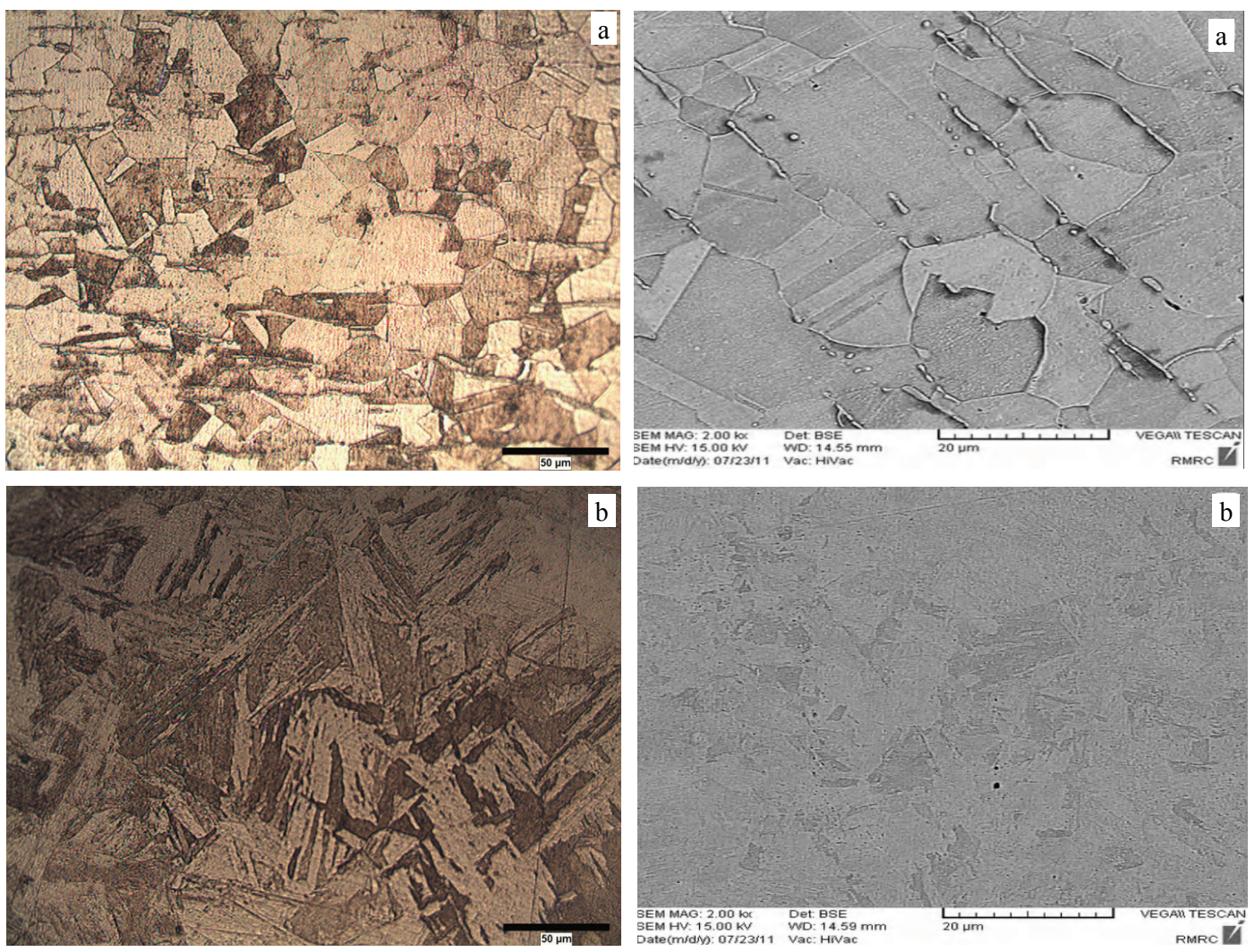

Fig. 1 SEM and OM images of the (a) martensitic and (b) austenitic substrates
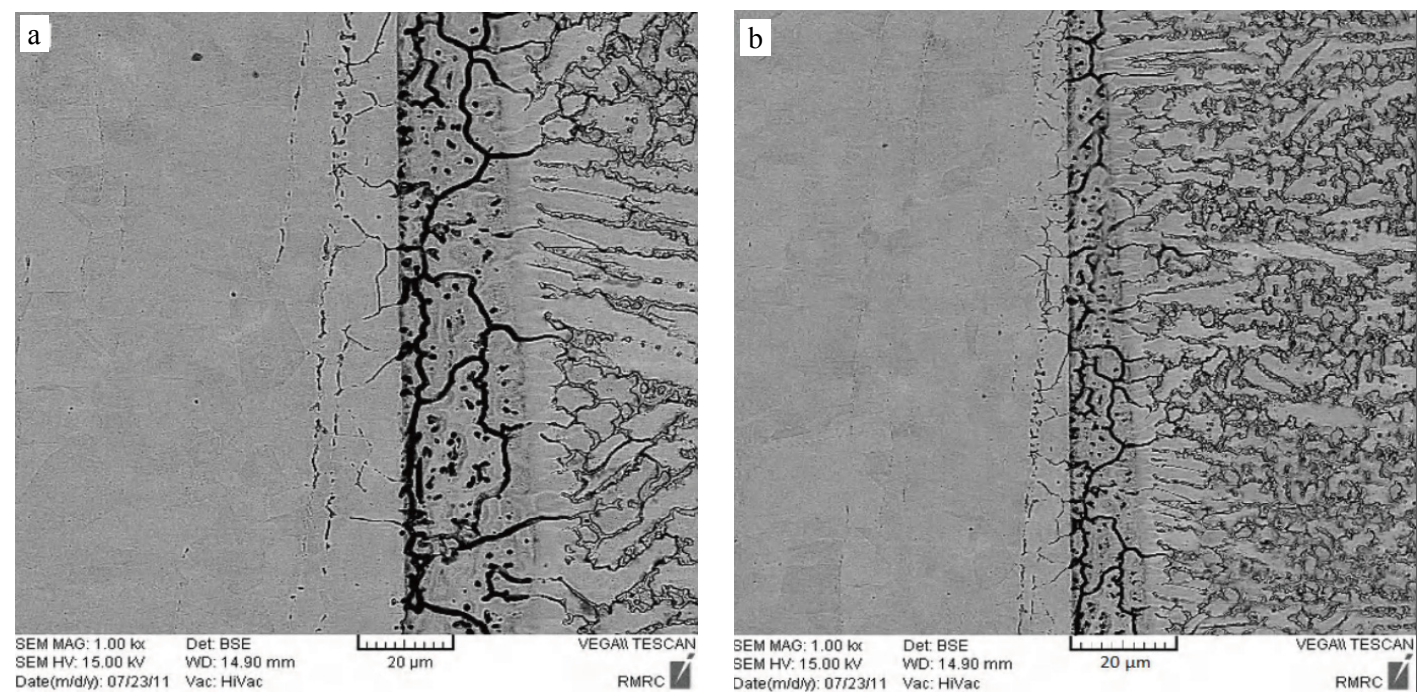

Fig. 2 The interface between coating and (a) martensitic and (b) austenitic substrates 
nar growth cannot be observed in this figure which can be ascribed to its low extension and limitation in magnification of optical microscope. Fig. 3 (a) presents the SEM image of the coating. The higher magnification SEM image of the area $\mathrm{A}$ is also depicted in Fig. 3 (a). With the aid of EDS analysis (Fig. 3b), it was found that the dendritic region consisted of $\mathrm{Cr}, \mathrm{C}$ and $\mathrm{Co}$ elements.

Stellite's microstructure is composed of a Co-rich, facecentered cubic a phase and inter-dendritic carbides ${ }^{11)}$, the Co-rich matrix with carbide particles are seen at grain boundaries.

According to the phase diagram of Stellite ${ }^{12)}$, the first stage of solidification is formation of a Co solid solution with a cellular and/or dendritic form. After that, the melt chemical composition located in the dendrite spacing becomes carbon and chromium rich and approaches eutectic composition with a laminated structure. Finally, with simultaneous solidification of the eutectic solid solution and eutectic carbides, the remained melt converts to solid.

The first stage of solidification is formation of a Co solid solution with a cellular and/or dendritic. After that, the melt chemical composition located in the dendrite spacing becomes carbon and chromium rich and approaches eutectic composition with a laminated structure.
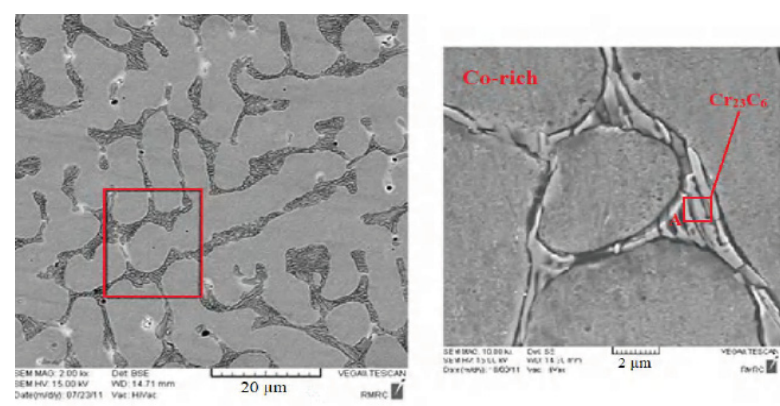

(a)

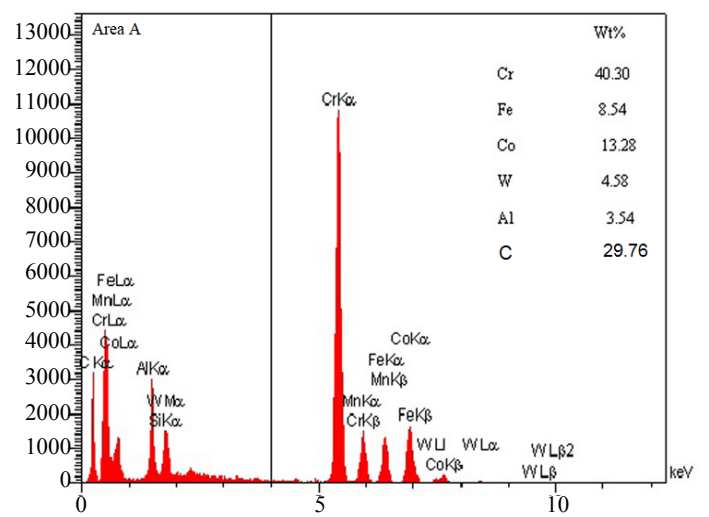

(b)

Fig. 3 (a) SEM image of the stellite coating structure and (b) The EDS result of the interdendritic region
Finally, with simultaneous solidification of the eutectic solid solution and eutectic carbides, the remained melt converts to solid.

The EDS analysis was used to determine the chemical composition of the present carbides in the inter-dendritic region. Fig. 3(b) depicts the EDS analysis results from the inter-dendritic region of the coating. Observing a significant amount of chromium in the results indicates that most of the carbides are chromium carbides. Due to using two substrate metals with different chemical compositions, distributions of nickel, cobalt, iron and chromium in the metal substrate and the cladding were investigated through line scan analysis.

Fig. 4 shows backscatter image of Stellite coating. Chromium rich carbides could be observable between dendritic arms (light gray).

Results of metallographic micrographs show that the microstructure consists of Cr-rich matrix (Co- 8 phase) and chromium carbide-rich eutectic. As it is obvious, presence of $\mathrm{Cr}$ and $\mathrm{Co}$ in the matrix is clear. The composition of the dark phases consisted of chromium carbides.

Fig. 5 shows SEM image of Stellite, including primary dendrites with dendritic structure.

For more investigation, The EDS analysis of A, B and C points of Fig. 5 were carried out. Results of The EDS analysis have been shown in Fig. 6.

Since the sensitivity of EDS is too poor to allow the detection of light elements like carbon, so, results are presented regardless of percentage of carbon.

According to Fig. 6, Spot A is the Cobalt-based matrix containing $\mathrm{Cr}$ and $\mathrm{Fe}$, Moreover Spot $\mathrm{B}$ is the black dendritic phase containing $\mathrm{Cr}$ and $\mathrm{C}$ which is almost the composition of chromium carbide $(\mathrm{Cr} 23 \mathrm{C} 6$ or Cr7C3). Furthermore there are considerable amounts of carbon and chromium in white precipitations (spot C). Considering results, it can be concluded that specific

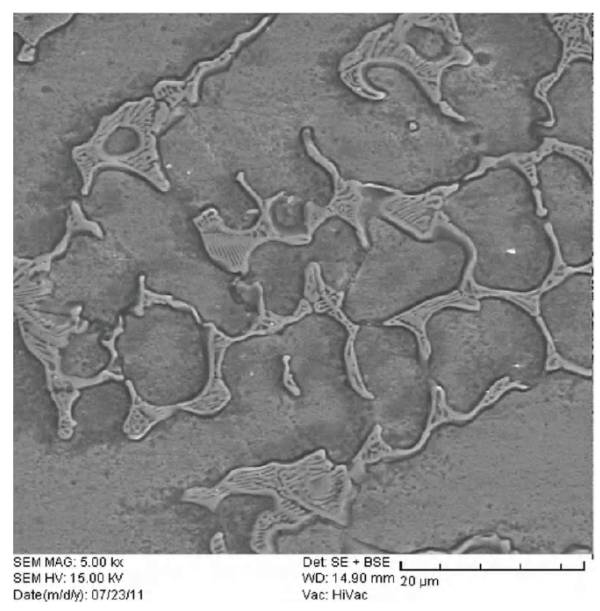

Fig. 4 Backscatter image of coating 


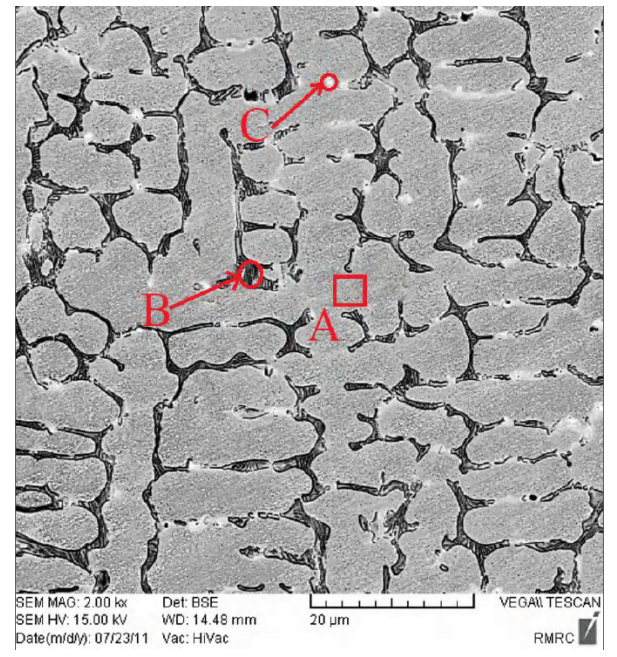

Fig. 5 SEM image of stellite
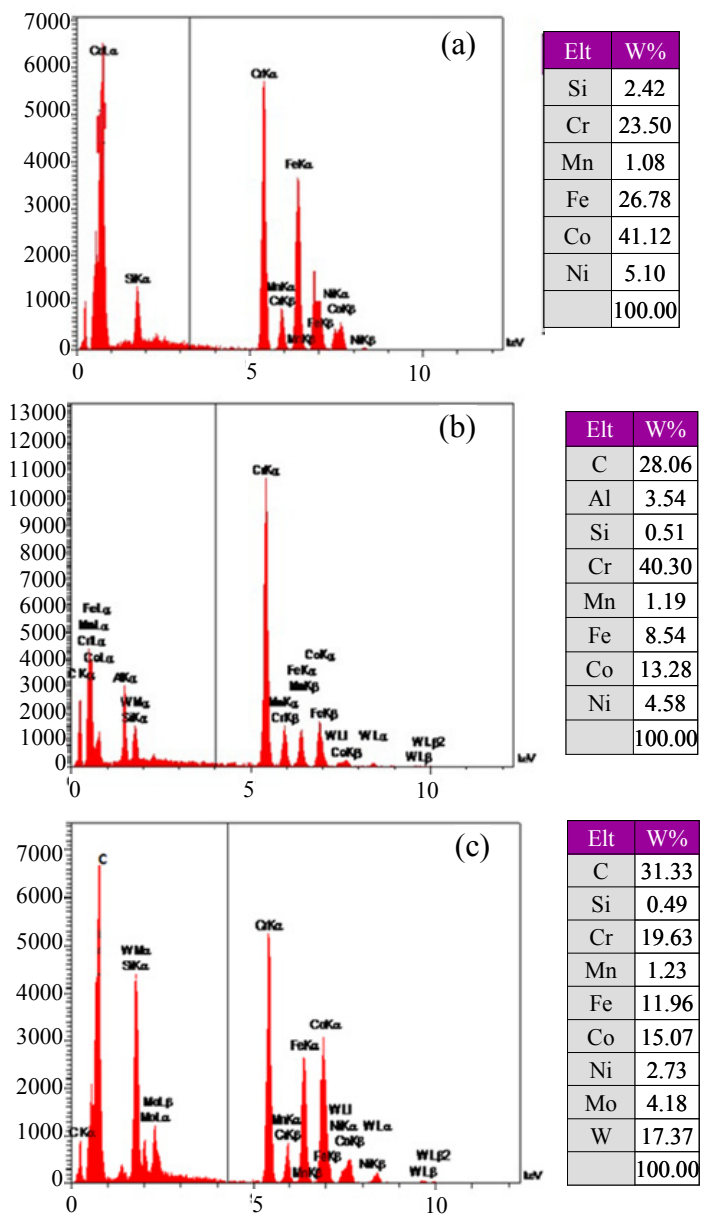

Fig. 6 (a), (b) and (c) spot analysis of A, B, C in Fig. 5

phases in this figures are carbides type of $\mathrm{Cr}_{\mathrm{m}} \mathrm{C} n$ and $\mathrm{CoC}_{\mathrm{m}}$ that correspond to results of other researchers ${ }^{2,10,13)}$.

In Fig. 7 with the aid of line scan EDS analysis the distributions of the elements in the (a) austenitic and (c) martensitic substrates is shown in the Fig. 7(b) and
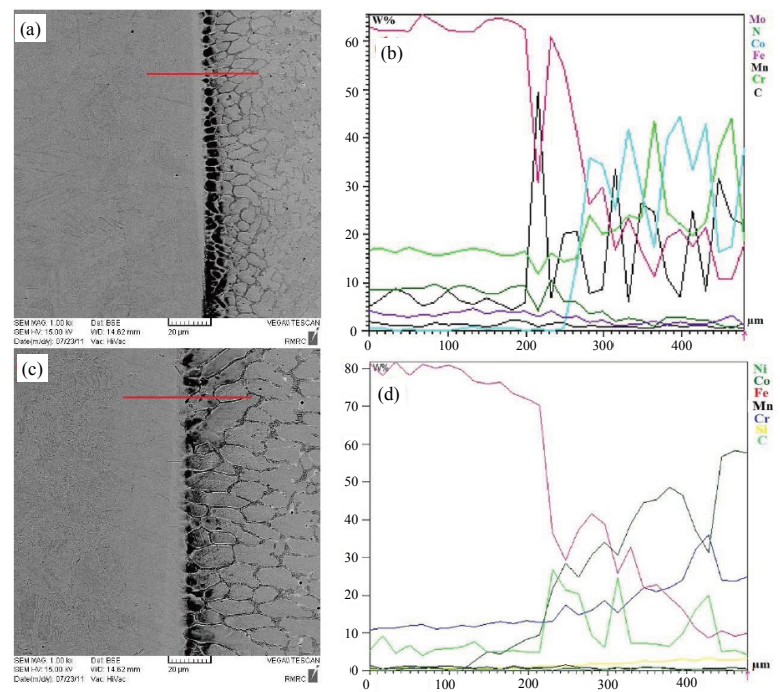

Fig. 7 The line scan region of the (a) austenitic and (c) martensitic substrates, (b) and (d) the EDS analysis of austenitic and martensitic substrates

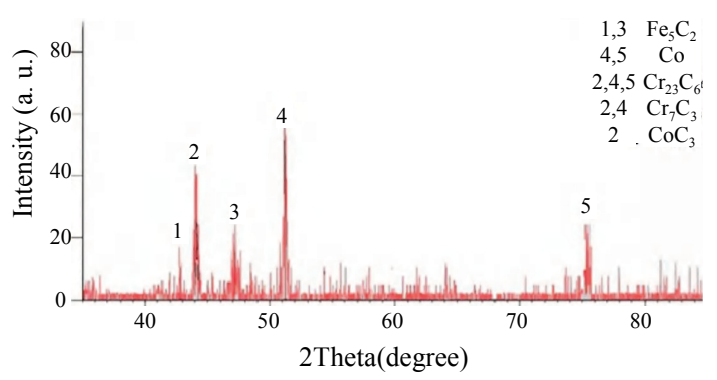

(a)

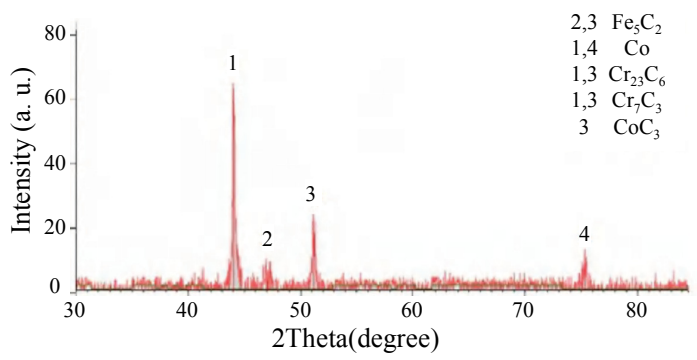

(b)

Fig. 8 The XRD patterns of the stellite cladding on the (a) austenitic substrate and (b) martensitic substrates

7(d), respectively.

It is found that in both substrates, from the interface to the coating, the concentrations of chromium and cobalt increase but the concentration of iron decreases. Also, the iron content in the coating for both substrates increases. According to the literature, the increased amount of iron in the coating increases the stacking fault energy in the cobalt lattice leading to decreased hardness, corrosion and erosion resistance of the coating ${ }^{7)}$.

Fig. 8 illustrates XRD patterns of the Stellite cladding for both substrates. In both investigated samples, the 
main constituent phase of the coating is face centered cubic (FCC) cobalt and the metastable phases such as $\mathrm{Cr}_{7} \mathrm{C}_{3}$ and $\mathrm{Cr}_{23} \mathrm{C}_{6}$ are $\mathrm{t}$ visible in the analysis result.

Fig. 9 depicts micro-hardness vs. the distance from the coating surface curves for (a) martensitic steel and (b) austenitic steel.

In both samples, the coating hardness is higher than the base metal hardness. Amounts of hardness changes from 200 vickers for substrates up to 600 vickers for coating, as it is illustrated in Fig. 9. Also, the hardness increases from the interface to the coating. As the EDS line scan analysis results show, the iron concentration in the close vicinity of the interface increases. With raising the iron content, the concentrations of chromium and cobalt decrease. Therefore, reduction of chromium carbide and accordingly reduction of solid solution hardness are expectable ${ }^{7}$. In other words, since the grains in the surface are finer than those in the interface, higher hardness in the surface grains is expectable. Because the substrate-coating in the interface is subjected to higher temperature during welding, the cooling rate is slower and the grain growth conditions in the interface are more appropriate compared with the surface ${ }^{6}$.

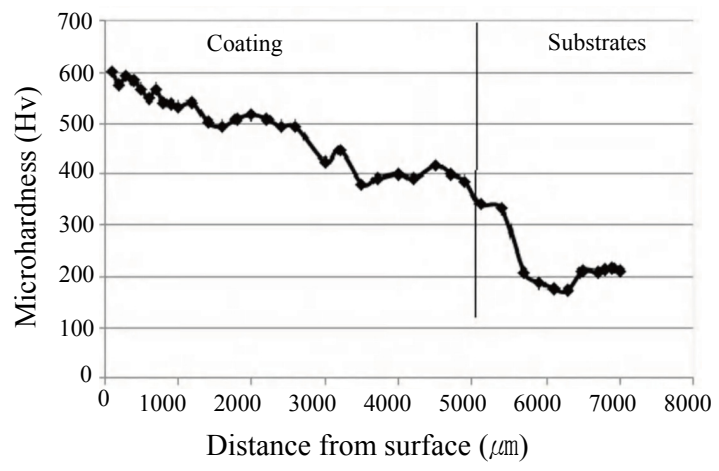

(a)

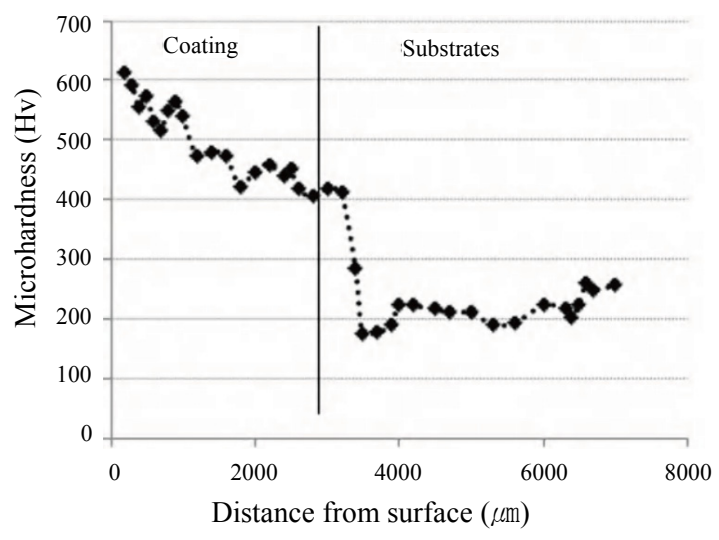

(b)

Fig. 9 The variation of the microhardness vs. the distance from the surface to the base metal: (a) martensitic and (b) austenitic

\subsection{Erosion and combined erosion and corrosion tests}

Fig. 10 shows the results of the erosion and combined erosion and corrosion tests. In this figure the total weight loss (TWL) measured after exposure to the impinging jet at $12 \mathrm{~m} / \mathrm{s}$ is shown for Coated Specimens. For comparison, stainless steels substrates 410 and 316 are also included. As can be seen, in both investigated samples, formation of the Stellite cladding has resulted in enhanced erosion resistance compared with that of the substrate specimens. The erosion resistance of coated specimens are 3 times better than Raw materials.

This enhancement can be ascribed to the presence of the hard carbide phases in the matrix as well as proper bonding of coating to the substrate metal. Comparing the results of the erosion and erosion- corrosion tests, it can be conclude that the effect of the corrosive medium on the increased rate of erosion in all the samples is significant. For example, the weight loss amount of the Stellite cladding on the austenitic stainless and martensitic steel in the corrosive medium increased from $3.6 \mathrm{mg} / \mathrm{h}$ to $9.1 \mathrm{mg} / \mathrm{h}$ and 4.4 to $10.2 \mathrm{mg} / \mathrm{h}$ respectively. Although the martensitic stainless steel is of higher erosion resistance than austenitic stainless steel due to its higher hardness, under combined conditions the extent of erosion in the martensitic substrate is greater owing to inherent higher corrosion resistance of austenitic stainless steel. These results are in good agreement with those reported by Lopez et al. ${ }^{14)}$. They showed that AISI304 stainless steel is of higher corrosion/erosion resistance than AISI420 stainless steel and concluded that inherent corrosion resistance is of a more important role in investigation of corrosion/erosion behavior than hardness. Comparing the erosion extent on both substrates shows that the formed Stellite cladding on AISI stainless steel has a higher erosion behavior than austenitic and martensitic stainless steel. This can be attributed to the distribution of the alloying elements in the coating. Owing to the presence of more chromium in the formed coating on the austenitic substrate more amounts of chromium carbide in the coating is expected.

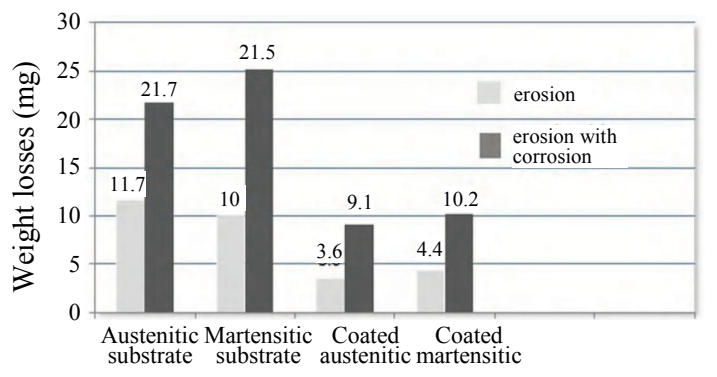

Fig. 10 The results of erosion and combined erosioncorrosion tests 

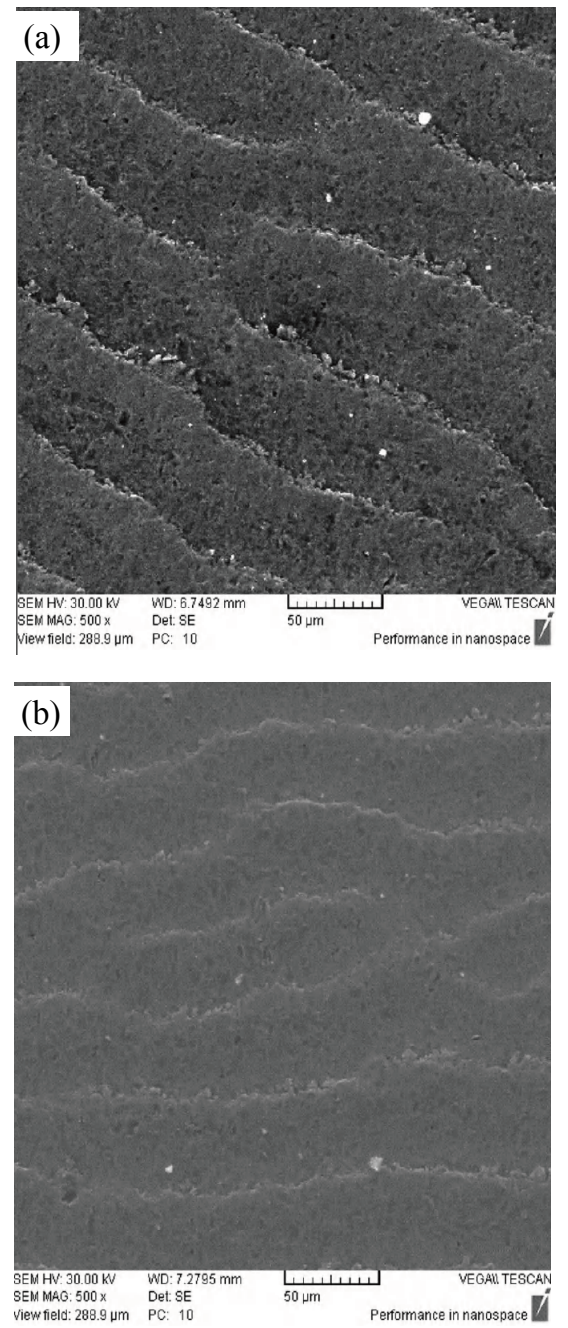

Fig. 11 SEM images of erosion in the (a) austenitic and (b) martensitic substrates

Nonetheless, due to more iron content in the martensitic steel than that in the austenitic steel, the iron content of the coating in the martensitic substrate is greater. Therefore, lower erosion resistance of the coating on the martensitic substrate is expectable. Fig. 11 shows SEM images of erosion in the austenitic and the martensitic substrates.

In both surfaces, the plastic deformations are observed in the form of parallel lines, from which, one can deduce that the martensitic steel exhibit ductile behavior despite higher hardness than austenitic steel. Lopez et al. ${ }^{14)}$ reported a ductile behavior against erosion in AISI420 stainless steel by conducting corrosion/erosion test. The relevant images will be presented in the next section. Also B.K. Sreedharinet al. ${ }^{15)}$ showed that in 316L stainless steel the accumulation of slip bands results in initiation of micro cracks. Plastic deformation then results in enlargement of the micro crack $s$ and void formation. The adjacent voids coalesce leading to material removal

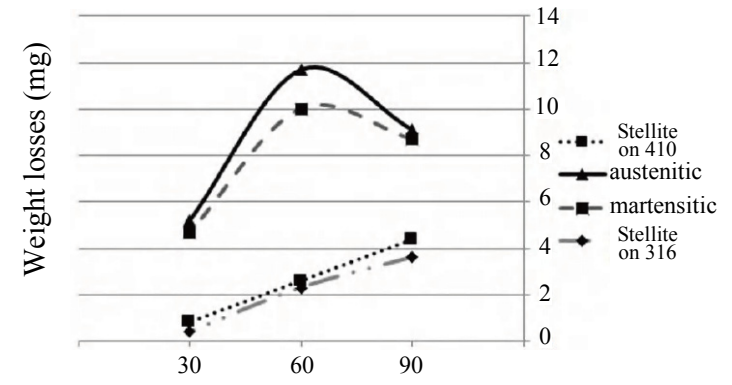

Angle of impingement/ degrees

Fig. 12 The results of erosion test on the substrates and on Stellite coating at different angle of impingements

\subsection{The effect of angle of impingement and deter- mining the erosion mechanism}

To investigate the effect of angle of impingement, the erosion test was carried out at 30 degree, 60 degree and 90degree on the substrates and Stellite cladding in which the results are presented in Fig. 12.

It is found that in uncoated substrates, the highest weight losses observed at 60 degree, also in both coated samples, the highest erosion rate is observed at 90 degree. Hence, it can be deduced that the Stellite cladding behavior is in agreement with the erosion theory of materials $^{6}$. This feature may be associated with the relatively complex microstructures of Stellite in that cast Stellite 6 has a ductile matrix but an extensive network of brittle chromium carbides, which may be exerting a signifi cant influence on the erosion-corrosion performance ${ }^{2)}$. Fig. 13 shows SEM images of erosion of the coating surface at the angle of impingements of (a) 30, (b) 60 and (c) 90 degrees.

In the Stellite's coating damage is initiated at the inter-face between the matrix and hard carbide locations ${ }^{15}$. At low angle of impingements, due to impact of abrasive particles with the surface, chip is formed which results in the formation of a lip with a plastic deformation. In the following, owing to impact of abrasive particles, the chips are broken and unbound from the surface. At high angle of impingements, first, lip is formed owing to impact of abrasive particles and in the following; crater is formed due to impact with the other abrasive particles. The formed lip on the surface is extended due to the next impacts resulting in thicker craters. Then, the extended lips are removed from the surface in the form of small planes ${ }^{2,6)}$.

\section{Conclusions}

The microstructure and the slurry erosion properties of Stellite 6 cladding formed by Gas Tungsten Arc Welding on the AISI316 and AISI410 stainless steel 

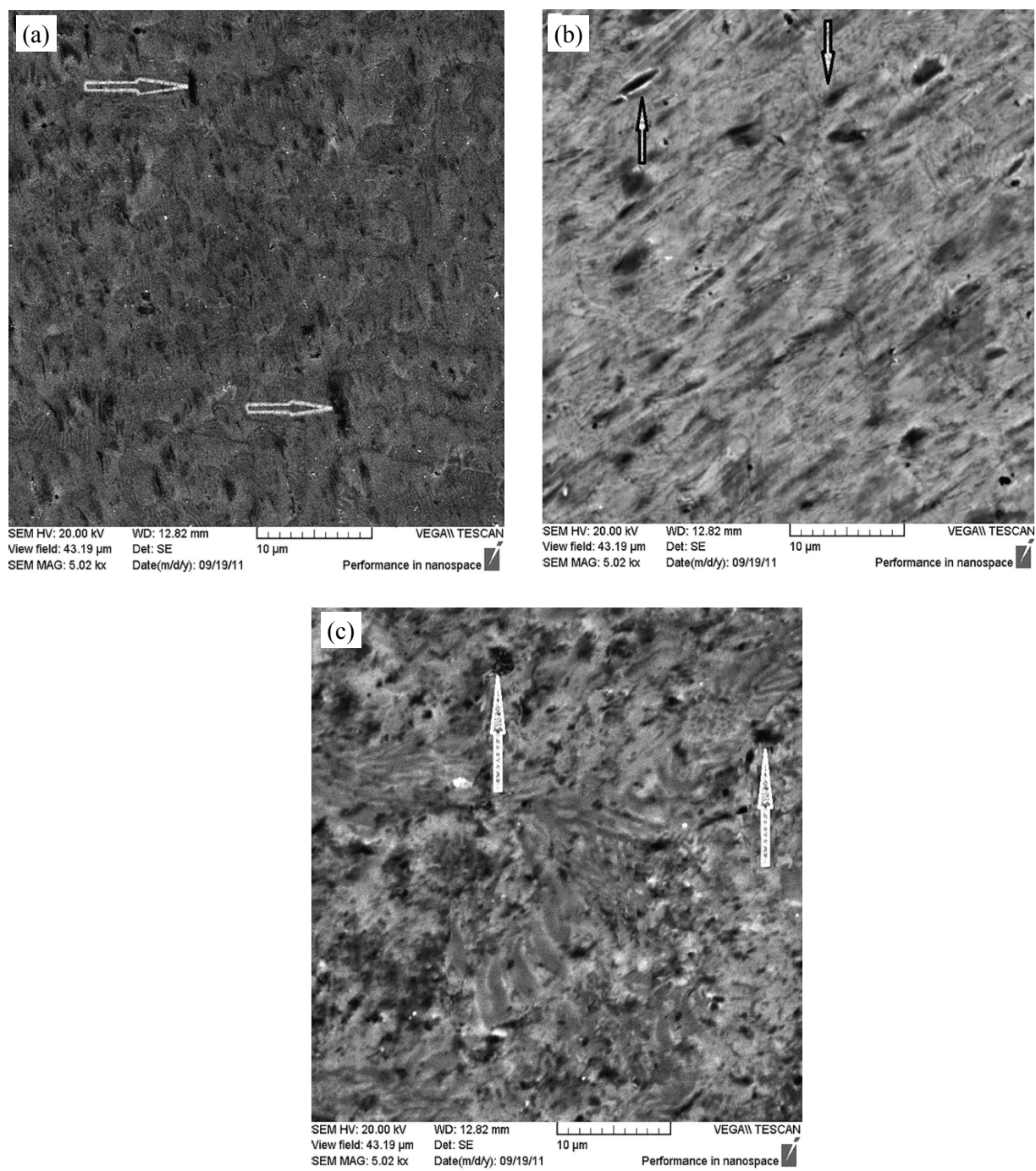

Fig. 13 SEM images of the erosion of the stellite coating at various angle of impingements: (a) 30, (b) 60 and (c) 90 degree

substrates have been studied. The major can be summarized as following,

- The microstructure of the Stellite cladding consists of a Co-rich solid solution with $\mathrm{Cr}$-rich carbides at the boundaries.

- The micro-hardness measurement results show that in both investigated samples, the hardness increases from the interface to the surface. Amounts of hardness changes from 200 vickers for substrates up to 600 vickers for coating, as it is illustrated in Fig. 9.

- The Stellite cladding caused significant improvement of the erosion resistance compared with the austenitic and martensitic substrates. The erosion resistance of Coated specimens are 3 times better than Raw materials.

- The effect of corrosive medium on increasing the erosion rate in all the investigated samples is noticeable. The formed Stellite coating on austenitic steel is of higher erosion resistance than martensitic steel.
This can be ascribed to the distribution of the alloying elements in the coating.

- The highest erosion rate is observed at the angle of impingement of 90degree. Hence, it is concluded that the Stellite coating behavior is in agreement with the erosion theory of brittle materials.

ORCID: B. Mousavi: https://orcid.org/0000-0003-2741-7554

ORCID: M. S. Shakeri: http://orcid.org/0000-0002-0701-4822

ORCID: A. Shamsipoor: https://orcid.org/0000-0001-6918-6323

\section{References}

1. C. S. Ramesh, R. Keshavamurthy, B. H. Channabasappa and S. Pramod, Influence of heat treatment on slurry erosive wear resistance of Al6061 alloy, J. Mater. Des. 30 (2009) 3713-3722.

2. N. Andrews, L. Giourntas, A. M. Galloway and A. Pearson, Effect of angle of impingement on the slurry erosioncorrosion of Stellite 6 and SS316, J. Wear, 320 (2014) 
143-151.

3. M. Sebastiani, V. Mangione, D. De Felicis, E. Bemporad and F. Carassiti, Wear mechanisms and in-service surface modifications of a Stellite 6 B Co-Cr alloy, J. Wear, 290-291 (2012) 10-17.

4. M. X. Yao, J. B. C Wu and Y. Xie, Wear, corrosion and cracking resistance of some W- or Mo-containing Stellite hardfacing alloys, J. Mater. Sci. Eng. A, 407 (2005) 234-244.

5. J. C. Shin, J. M. Doh, J. K. Yoon, D. Y. Lee and J. S. Kim, Effect of molybdenum on the microstructure and wear resistance of cobalt-base satellite hardfacing alloys, $J$. Surf. Coat. Technol. 166 (2003) 117-126.

6. R. C. Shivamurthy, M. Kamaraj, R. Nagarajan, S. M. Shariff and G. Padmanabham, Slurry erosion characteristics and erosive wear mechanisms of Co-based and $\mathrm{Ni}$ based coatings formed by laser surface alloying, $J$. Metall. Mater. Trans. A, 41A (2010) 470-486. https://doi.org/10.1007/s11661-009-0092-y

7. A. Gholipour, M. Shamanian and F. Ashrafizadeh, Microstructure and wear behavior of Stellite 6 cladding on 17-4PH stainless steel, J. Alloys and Compd. 509 (2011) 4905-4909.

8. G. Xu, M. Kutsuna, Z. Liu and K. Yamada, Comparison between diode laser and TIG cladding of Co-based alloys on the STS403 stainless steel, J. Surf. Coat. Technol. 201 (2006) 1138-1144.
9. S. Hattori, N. Mikami, Cavitation erosion resistance of Stellite alloy weld overlays, J. Wear, 267 (2009) 19541960.

10. R. Jendrzejewski and A. Conde, Characterization of the laser-clad Stellite layers for protective coatings, $J$. Mater. Des. 23 (2002) 83-88.

11. S. A. Romo, J. F. Santa, J. E. Giraldo and A. Toro, Cavitation and high-velocity slurry erosion resistance of welded Stellite 6 alloy, J. Tribology Int. 47 (2012) 16-24. https://doi.org/10.1016/j.triboint.2011.10.003

12. L. Fouilland, M. El Mansori and A. Massaq, Frictioninduced work hardening of cobalt-basehardfacing deposits for hot forging tools, J. Mater. Process. Technol. 209 (2009) 3366-3373.

13. Kuzucu and V. Ceylan, An investigation of Stellite-6 alloy containing $5.0 \mathrm{wt} \%$ silicon, J. Mater. Process. Technol. 79 (1998) 47-51.

14. D. Lopez, J. P. Congote, J. R. Cano, A. Toro and A. P. Tschi-ptschin, Effect of particle velocity and angle of impingement on the corrosion-erosion of AISI 304 and AISI 420 stainless steel, J. Wear, 259 (2005) 118-124.

15. B. K. Sreedhar, S. K. Albert and A. B. Pandit, Improving cavitation erosion resistance of austenitic stainless steel in liquid sodium by hardfacing-comparison of $\mathrm{Ni}$ and Co based deposits, J. Wear, 342-343 (2015) 92-99. https://doi.org/10.1016/j.wear.2015.08.009 